\title{
Clinico-Radiological Spectrum of Neuronal Migrational Disorders: A Study of Paediatric Patients in the Western Region of Nepal.
}

Swain PK, ${ }^{1}$ Dhaliwal MS ${ }^{2}$, Thapalial $\mathrm{A}^{3}$,Tiwari PK ${ }^{4}$.

${ }^{1 .}$ Dr. Pradeep Kumar Swain, Associate Professor, ${ }^{2 .}$ Dr. M. S. Dhaliwal, Assistant Professor, ${ }^{3 .}$ Dr. Anna Thapalia, Professor and HOD, Department of Paediatrics, ${ }^{4}$ Dr. P. K. Tiwari, Professor and HOD, Department of Radiodiagnosis, Manipal College of Medical Sciences (MCOMS), Pokhara, Nepal.

Address of correspondence: pkswain1 @ rediffmail.com

\begin{abstract}
:
Objective: This study was conducted in a tertiary care paediatric hospital to ascertain the spectrum of clinical and radiological features of Neuronal Migrational Disorders in children. The role of inheritance in Neuronal Migrational Disorders is under intense investigation. Studies on Neuronal Migrational Disorders (NMDs) in children from developing countries are lacking. Method: Retrospective analysis of records of diagnosed cases by neuroimaging as Neuronal Migrational Disorders in the Department of Paediatrics. Results: Eighteen Children (2days to 8 years age) with different types of neuronal migrational disorder based on neuro-imaging were included. Observed anomalies included Lissencephaly (33.3\%), Pachygyria (16.6\%), Polymicrogyria (5.5\%), Heterotopia (11.1\%), Schizencephaly (22.2\%) and Hemimegalencephaly (5.5\%). Focal Seizure in $5(27.7 \%)$ cases, Generalised Tonic Clonic Seizures in $3(16.6 \%)$ and Myoclonic Seizure in $2(11.1 \%)$ cases were the types of seizure present in 10 $(55.5 \%)$ patients. Five patients presented with Quadriparesis, two with Hemiplegia and one with Congenital Talipes Equinovarus. All the eighteen patients had some degree of Cognitive Developmental Delay. Conclusion: Lissencephaly is the most common type of Neuronal Migrational Disorder followed by Schizencepahly. Focal Seizure and Quadriparesis were the common manifestations. Family history of similar cases with parental consanguinity in Schizencephaly cases gives a clue to the autosomal recessive mode of inheritance. Family history of similar cases of Schizencephaly without any history of consanguinity indicates an autosomal pattern of inheritance.
\end{abstract}

Key words: Neuronal Migrational Disorders, Lissencephaly, Schizencephaly, Cognitive Developmental Delay and Neuro-imaging.

\section{Introduction:}

Developmental Central Nervous System (CNS) malformations are a complex group of congenital malformations often presenting with variable neurodevelopmental dysfunction and seizures ${ }^{\mathbf{1}}$. Among them Neuronal Migrational Disorders (NMDs) is the result of disturbed brain development due to defective neuroblast migration in the early gestation. In such disorders, neurones are abnormally located or there is an absence of migration of neurobalst ${ }^{2}$. They have been recognized for more than 100 years ${ }^{3}$. NMDs of the brain have recently been identified as a major cause of Cognitive Developmental Delay (CDD) and intractable epilepsy ${ }^{\mathbf{4} 5}$. NMDs include; Schizencephaly (unilateral or bilateral grey matter line cleft of lateral cerebral wall extending from periventricular zone to the meninges), Lissencephaly (brain appears smooth with few gyri), Pachygyria (thickened gyri), Polymicrogyria (excessive small windings), Neuronal Heterotopia (collections of neuronal arrests in the subcortical white matter), Periventricular Nodular Heterotopia (absence of migration of Neuroblast from periventricular region), Brain Warts (marginal glioneural heterotopia), Non-neoplastic Ventricular Mass, Double Cortex or Band Heterotopia and Hemimegalencephaly (dysplastic enlargement of the lateral ventricles on the affected side associated with gray and white matter malpositioning $\mathbf{1 , 5 , 6}$. Computed Tomography (CT) Scan and Magnetic Resonance Imaging (MRI) of brain have revolutionized our understanding of these malformations, providing a good anatomic diagnosis. However, accurate pathological diagnosis can be done by histopathology only. We conducted the present study to evaluate clinical spectrum of NMD's in children as diagnosed by neuro-imaging in the western region of Nepal.

\section{Methods:}

All the children with the diagnosis of NMD over a seven years period from 2001 to 2007 at the Manipal College of Medical Sciences and Teaching Hospital (a tertiary care hospital), Department of Paediatrics in the western region of Nepal were included in study. These children were evaluated for age at seizure onset, sex, risk factors, parental consanguinity, family history, antenatal history, gestational period, developmental delay, dysmorphic features, seizure semiology, neurological examination and other associated clinical conditions. CT scan of brain was done in all the total of eighteen (18) cases and MRI was done for further confirmation in two (2) cases only, which was because MRI is not available in this region. The same neuro-radiologist reviewed all the CT scans. Electroencephalograms (EEG) was performed in cases with doubtful seizure semiology, to identify the seizure type and concomitant EEG abnormality. Brain CT scans were performed on a GE Helical CTE; CT scanner with systematic study from vertex to foramen magnum at 9-mm intervals. EEGs were obtained using the international 
10-20 system and recorded on a 23 Specialized Laboratory Equipment machine in ten (10) patients having seizures.

\section{Results:}

A total Of 18 patients were included in the study. There were 10 boys and 8 girls. Mean age at onset of clinical presentations was 1.6 years (2 days-8years). Distribution of different types of NMD's in the study series were Lissencephaly 6 (33.33\%), Schizencephaly 4 (22.22\%), Pachygyria 3 (16.67\%), Polymicrogyria 1 (5.56\%), Heterotopia $2(11.11 \%)$ and Hemimegalencephaly $2(11.11 \%)$. Two of the Lissencephaly cases had Complete Agenesis of the Corpus Callosum. One of the Schizencephaly had unilateral parietal lobe closed lip and other three had unilateral open lip Schizencephaly. Four patients had other associated anomalies (Table-I). All 18 patients had some degree of cognitive developmental delay, $10(55.55 \%)$ had seizures, $5(27.77 \%)$ had Quadriparesis, one $(5.55 \%)$ had Congenital Talipes Equinovarus [CTEV] and $2(11.11 \%)$ had Hemiplegia.
EEG was done in all the 10 seizure cases. Hypsarrythmia and high voltage fast activity were the commonest abnormality in 6 cases followed by Multifocal Epileptiform activities in 2 cases and Generalized Polyspike slow waves in 2 cases.

All patients were diagnosed by brain CT scan and MRI further confirmed the diagnosis in 2 patients only (Table-I). Parental consanguinity was documented in $6(33.33 \%)$ patients of whom 3 (16.66\%) had Lissencephaly, 2 (11.11\%) Heterotopia and one $(5.55 \%)$ had pachygyria. Family history of similar cases was documented in 6 patients ( 4 in Lissencephaly along with 2 in Schizencephaly) which suggested an autosomal recessive pattern of inheritance in Lissencephaly patients and autosomal dominant pattern in Schizencepahly.

Table-I: Clinical Data's and Investigations in 18 Patients with NMD.

\begin{tabular}{|c|c|c|c|c|c|c|c|}
\hline \multirow[t]{2}{*}{ Case number(n)-18 } & \multirow{2}{*}{$\begin{array}{l}\text { Associated } \\
\text { conditions }\end{array}$} & \multicolumn{2}{|c|}{ Clinical presentations } & \multirow[t]{2}{*}{ MRI } & \multirow[t]{2}{*}{ EEG } & \multirow{2}{*}{$\begin{array}{l}\text { Family } \\
\text { history }\end{array}$} & \multirow[t]{2}{*}{ Consanguinity } \\
\hline & & Seizure & others & & & & \\
\hline $\begin{array}{l}\text { Lissencephaly } \\
\mathrm{n}=6(33.33 \%),\end{array}$ & $\begin{array}{l}\text { Agenesis of } \\
\text { corpus callosum(2) }\end{array}$ & GTCS-2* & Quadriparesis(4) & & 4 & 4 & 3 \\
\hline $\begin{array}{l}\text { Schizencephaly } \\
\mathrm{n}=4(22.22 \%)\end{array}$ & & FS-2 & Hemiplegia(2) & & 2 & 2 & \\
\hline $\begin{array}{l}\text { Pachygyria } \\
n=3(16.67 \%),\end{array}$ & Microcephaly(1) & MS-2 & Quadriparesis(1) & & 1 & & 1 \\
\hline $\begin{array}{l}\text { Heterotopia } \\
\mathrm{n}=2(11.11 \%)\end{array}$ & & $\mathrm{FS}-2^{\dagger}$ & & 1 & 1 & & 2 \\
\hline $\begin{array}{l}\text { Polymicrogyria } \\
\mathrm{n}=1(5.56 \%)\end{array}$ & & & $\operatorname{CTEV}(1)^{\S}$ & 1 & 1 & & \\
\hline $\begin{array}{l}\text { Hemimegalencephaly } \\
\mathrm{n}=2(11.11 \%)\end{array}$ & Hydrocephaly(1) & $\begin{array}{l}\text { GTCS-1 } \\
\text { FS-1 }\end{array}$ & & & 1 & & \\
\hline
\end{tabular}

NB: *GTCS - Generalized Tonic Clonic Seizure, †FS-Focal Seizure, ¥MS-Myoclonic Seizure, § CTEV - Congenital Talipes Equino Varus.

Age at onset of seizure was in the neonatal period in 3 patients, 2-8 months in 2 patients and after 1 year in 5 patients. Seizure at the onset was Myoclonic in 2, Generalized Tonic Clonic in 3 patients and Focal in 5 patients. 2 patients had Myoclonic Seizure and 3 patients with Generalized TonicClonic seizure subsequently developed Infantile Spasm. Focal Epilepsy was the predominant type of seizure followed by GTCS 7 Myoclonic seizure. Pattern of seizure and other clinical presentations in relation to the $\mathrm{CT}$ findings is shown as in Table-I. During the same period 204 Cognitive Developmental Delay (CDD) alone, 268 seizures alone and $98 \mathrm{CDD}$ and seizures both were diagnosed in the paediatrics department. Incidence of NMD's was $8.8 \%$ in CDD alone, $6.0 \%$ in seizure alone and $18.3 \%$ in both the CDD and seizure.
Figure I : CT scan images showing Schizencephaly (closed lip type)

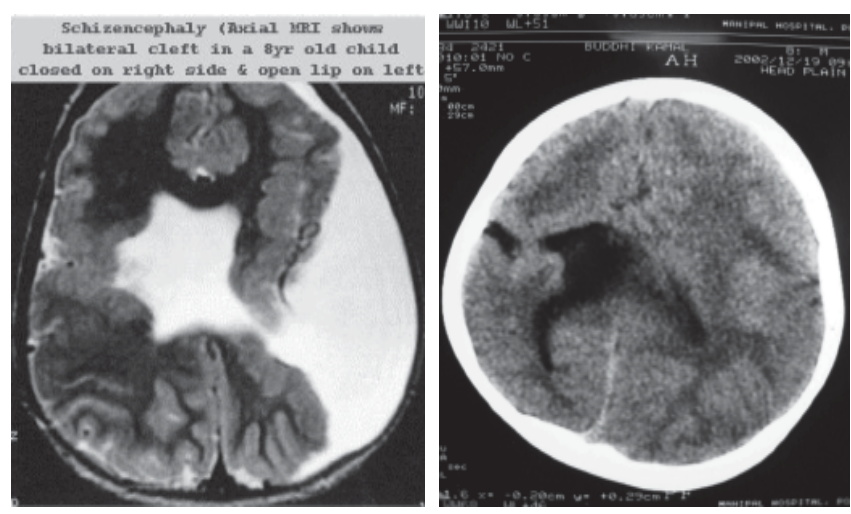




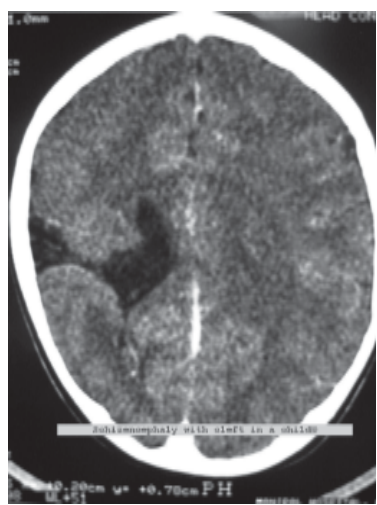

\section{Discussion:}

NMDs represent abnormalities of neuronal migration occurring in the period 2-5 months post-conception ${ }^{2}$. Nearly all malformations of the brain are direct results of faulty migration or at least a secondary impairment of migration. Imperfect cortical lamination, abnormal gyral development, subcortical heterotopia and other focal dysplasia are related to some factor that interferes with neuronal migration, whether vascular, traumatic, metabolic or infectious . All the NMDs occur mostly during the 8 weeks to 20 weeks of gestation . Incomplete neuroblast migration in the early pregnancy leads to Heterotopias. Smooth cerebral cortex without convolutions is called as Lissencephaly or agyria which occurs at the midgestation due to genetic causes and also in intrauterine infections. Schzencephaly is a unilateral or bilateral deep cleft usually in general position of sylvian fissure but is not a sylvian fissure and occurs as a genetic traits $\&$ sporadically also ${ }^{6}$.

The exact aetiology behind NMDs is not known, but pathological processes disruptive to migration include hypoxic-ischaemic encephalopathies, inborn errors of metabolism, congenital infections, chromosomal abnormalities, genetic defects, and prenatal exposure to cocaine and other street drugs ${ }^{7,8}$. Volpe stated that sporadic cases of Lissencephaly are more common than familial varieties, contrary to Barth who stated that Lissencephaly is usually due to Mendelian Inheritance or Chromosomal Disorders ${ }^{9,10}$. The extremely high rate of parental consanguinity among Lissencephalic patients $(66.66 \%)$ and family history of possible similar cases with autosomal recessive inheritance $(50.00 \%)$ in the present study support the genetic etiology of lissencephaly. The genes responsible for two types of Lissencephaly were mapped to chromosome 9q31-33 and chromosome Xq22.3 ${ }^{11,12}$. Mutations of the XLIS (or DCX) gene and of the LIS1 gene on chromosome 17 recently found in the cases of Lissencepahly ${ }^{23}$.

Familial occurrence of Schizencephaly in $50.00 \%$ of cases was found in this study. Familial cases of schizencephaly have been reported, raising the possibility of an autosomal dominant inheritance with incomplete penetrance and variable expression ${ }^{13}$. The role of inheritance in other nonlissencephalic NMDs is not clear in the literature and the small number of patients in the present study does not allow definite suggestions (Table I). Parental consanguinity was also found in cases of Pachygyria and Heterotopia. Straussberg et al ${ }^{14}$. Reported a case of autosomal recessive Pachygyria.
Technically optimal CT is effective in detecting different types neuronal migartional disorder but MRI is more specific than $\mathrm{CT}^{15}$. All patients in the present study were investigated by Spiral-CT and only two of them had their diagnosis further confirmed by MRI.

Seizure disorder and cognitive developmental delay which was the major clinical presentations in this study was reported by other workers also $16,17,1,19$. With a small sample size in the present study NMDs still represent $8.8 \%$ in CDD alone, $6.0 \%$ in seizure alone and $18.3 \%$ in both the $\mathrm{CDD}$ and seizure. The results of the present study are comparable to those of Brodtkorb et al. who found that $4.3 \%$ of patients with epileptic seizures and $13.7 \%$ of patients with seizures and mental retardation had NMDs ${ }^{20}$. All patients in the present study had some degree of cognitive developmental delay of variable severity. Fifty percent of seizures were in the neonatal period in the study which was in accordance with the Gestaut et al ${ }^{21}$. Quadriparesis and GTCS was the predominant manifestation in Lissencephaly patients which was similar to the report by Guerrini et al ${ }^{22}$.

Schizencephaly has a wide anatomo-clinical spectrum (closed lip and open lip), including focal epilepsy in most patients, which was also reflected in our study ${ }^{23}$. Familial occurrence is rare but in our study it was 50\% among four patients without any history of consanguinity thus indicating an autosomal dominant pattern of inheritance, which needs further study. However at present, there is no clear indication on the possible pattern of inheritance and on the practical usefulness that mutation detection in an individual with schizencephaly would carry in terms of genetic counseling ${ }^{23}$.

\section{Conclusion:}

In conclusion this present study reflects the incidence of possibly inherited NMDs like Lissencepahly is much higher than other forms. Neuronal Migrational Disorder in children is still the predominant cause of epilepsy and developmental delay. Association of Schizencephaly in families without parental consanguinity indicative of autosomal dominant pattern of inheritance but which needs further evaluation and study in a larger scale. Parental consanguinity is also present in other types of NMDs including Lissencephaly. More genetic work is required to determine their etiologies.

\section{References:}

1. Osborn AG. Normal Brain Development and General Classification of Congenital Malformations. In: Osborn AG, editor. Diagnostic Neuroradiology. 1st ed. St Louis, Mosby-Yearbook, 1994. p 3-14.

2. Schaefer BG, Sheth RD, Bondensteincr JB. Cerebral Dysgenesis. Neurologic Clinics 1994; 12: 773-88.

3. Martell M. Ein Fall Von Heterotopic Der Frauen Substance in Den Beiden Hemispherens Des Gronsshirns. Arch Psychiatr Nervenkr 1893; 25: 12436.

4. Barth PG. Migrational Disorders Of The Brain. Curr Opin Neural Neurosurg 1992; 5: 339-43. 
5. Hanefeld F. Pediatric and Developmental Neurology. Curr Opin Neural Neurosurg 1992; 5: 331-2.

6. Walter G. Bradley,Robert B.Daroff, Gerald M.Fenichel \& Joseph Jankovic, Neuology in Clinical Practice, VolI; $4^{\text {th }}$ edition ,p-1763- 1786 .

7. Barth PG. Schizencephaly and Nonlissencephalic Cortical Dysplasia. Am J Neural 1992; 13: 104-8.

8. Domingues R, Aguirre Vila-Coro, Slopis JM, Bohan TP. Brain and Abnormalities In Infants With In Utero Exposure to Cocaine and other Street Drugs. Am J Dis Child 1991; 145: 688-95.

9. Barth PG. Schizencephaly and Nonlissencephalic Cortical Dysplasia. Am J Neural 1992; 13: 104-8.

10. Volpe JJ. Neuronal Proliferation, Migration, Organization And Myelination. Major Problems In Clinical Pediatrics. In: Volpe JJ (Ed.) Neurology of the Newborn, 2nd edn. W.B. Saunders Co, Philadelphia, 1987; 22: 37-60.

11. Toda T, Segawa M, Namuray, el al. Localization of Gene for Fukuyama Type Congenital Muscular Dystrophy to Chromosome 9q31-33. Nature Genet 1993; 5: 283-6.

12. Dobyns WB, Andermann E, Andermann F, el al. $X$ Linked Malformations of Neuronal Migration. Neurology 1996; 47: 331-9.

13. F. Haverkamp, K. Zerres, B. Ostertun, D. Emons and M.J. Lentze, Familial Schizencephaly: Further Delineation of a Rare Disorder. J Med Genet 32 (1995), pp. 242-244.

14. Straussberg R, Gross S, Amir J, Gadoth N. A New Autosomal Recessive Syndrome of Pachygyria. Clin Genet 1996; 70: 155-8.
15. Gao PY, Zhonghua fang she xue za zhi. CT Diagnosis Of Neuron Migration Anomalies; Chinese Journal of Radiology 1989 Feb;23(1):2-4.

16. Turjman F, Massoud TF, Sayre JW, Vinuela F, Guglielmi G, Duckwiler G. Epilepsy Associated with Cerebral Arteriovenous Malformations. Multivariate Analysis of Angioarchitectural Characteristics. Am J Neuroradiol 1995; 16: 345-50.

17. Sperling MR. Neuroimaging in Epilepsy: Recent Developments in MR Imaging, Positron-Emission Tomography, and Single Photon Emission Tomography. Neurologic Clinics 1993; 11:883-903.

18. Smith AS, Weinstein MA, Quencer RM, el al. Association of Heterotopic Gray Matter with Seizures, MR Imaging. Radiology 1988; 168: 195-8.

19. Altman N, Birchansky S, Goldstein R, el al. Preliminary Report of Neuroimaging And Pathological Correlations in Children Operated on for Intractable Focal Epilepsy. Int Pediatr 1994; 9 : 85-93.

20. Brodtkorb E, Nilsen G, Smevik O, Rinck PA. Epilepsy and Anomalies of Neuronal Migration: MRI and Clinical Aspects. Acta Neural Scand 1992; 86: 24-32.

21. Gastaut H, Pinsard N, Raybaud C, Aicardi J, Zifkin B. Lissencephaly (Agyria-Pachygyria) Clinical Findings and Serial EEG Studies. Dev Med Child Neurol 1987; 2: $167-80$.

22. Guerrini R, Sicca F, parameqqiani L. Epilepsy and Malformation of CNS. Epileptic Disord,2003;sept. 5 suppl 2: s 9-26.

23. Guerrini R and Carrozzo R. Epileptogenic Brain Malformations: Clinical Presentation, Malformative Patterns and Indications for Genetic Testing ,Seizure. 2002 Apr;11 Suppl A:532-43; quiz 544-7. 